\title{
O USO DOS EQUIPAMENTOS DE PROTEÇÃO INDIVIDUAL ENTRE OS TRABALHADORES DE ENFERMAGEM ACIDENTADOS COM INSTRUMENTOS PERFUROCORTANTES ${ }^{1}$
}

\author{
THE USE OF INDIVIDUAL PROTECTION EQUIPMENT AMONG NURSING \\ WORKERS INJURIED BY PUNCTURE-CUTTING INSTRUMENTS
EL USO DE LOS EQUIPOS DE PROTECCIÓN INDIVIDUAL ENTRE LOS TRABAJADORES DE ENFERMERÍA ACCIDENTADOS CON INSTRUMENTOS PERFUROCORTANTES

Leila Maria Mansano Sarquis ${ }^{2}$

Vanda Elisa Andres Felli $i^{3}$

\begin{abstract}
RESUMO: O presente estudo analisou os acidentes de trabalho ocorridos com trabalhadores de enfermagem em um hospital público do interior de São Paulo. A amostra foi composta por todos os trabalhadores de enfermagem. Os resultados obtidos mostram a significativa freqüência de acidentes com instrumentos perfurocortantes. Nesse tipo de acidente, os mais altos foram encontrados na categoria auxiliar de enfermagem, o que mostra também que o trabalhador de enfermagem muitas vezes não utiliza o equipamento de proteção individual, mesmo que seja fornecido no local de trabalho. A manipulação de instrumentos perfurocortantes por profissionais dessa área mostra a grande exposiçäo aos riscos biológicos e graves doenças. Esses resultados, evidenciam a necessidade de prevenir tais acidentes.
\end{abstract}

PALAVRAS - CHAVE: acidentes de trabalho, instrumentos perfurocortantes, enfermagem.

\section{INTRODUÇÂO}

O trabalho de enfermagem na instituição hospitalar caracteriza-se pelo cuidado nas 24 horas do dia, permitindo a continuidade da assistência aos pacientes. Nesse cuidado aos pacientes, os trabalhadores de enfermagem utilizam instrumentos de trabalho como: agulhas, lâminas de bisturi, tesouras, pinças, materiais de vidro e muitos outros instrumentos que são perfurantes e cortantes.

Diante dessa problemática, nos interessa aprofundar a reflexão e a geração de conhecimentos a respeito dos acidentes com materiais perfurocortantes a que estão expostos os trabalhadores de enfermagem de um hospital, bem como conhecer como se dá a utilização dos equipamentos de proteção individual.

Em 1919 é editada a primeira lei de acidente de trabalho. Em 1994, a Portaria no 3.214,

'Elaborado a partir da dissertação de mestrado "Acidentes de trabalho com instrumentos perfurocortantes: ocorrência entre os trabalhadores de enfermagem", defendida em novembro de 1999 na Escola de Enfermagem da Universidade de São Paulo.

${ }^{2}$ Enfermeira. Profa Ms. da Universidade Tuiuti do Paraná, do Curso de Graduação em Enfermagem da Disciplina de Administração em Enfermagem.

${ }^{3}$ Enfermeira. Prof ${ }^{a}$. Dr ${ }^{2}$ do Departamento de Orientação Profissional da Escola de Enfermagem da Universidade de São Paulo. 
de 8 de junho de 1978, aprova as Normas Regulamentadoras-NRs. A NR 7 dispõe sobre a obrigatoriedade e a implementação do Programa de Controle Médico de Saúde Ocupacional, com o objetivo de promover e preservar a saúde do conjunto dos seus trabalhadores. (BRASIL, 1997a). Por sua vez, a NR 9 estabelece a obrigatoriedade da elaboração de um programa de prevenção de riscos ambientais no trabalho, considerando a proteção do meio ambiente e dos recursos naturais. Indica a adoção de equipamentos de proteção coletiva-EPC bem como, quando for necessário, em caráter complementar, a utilização de equipamentos de proteção individual-EPI. Embora existam todos esses dispositivos legais que buscam prevenir e preservar a saúde do trabalhador, garantindo seus direitos, na prática, esbarram em grandes dificuldades que dizem respeito à necessidade de estabelecimento de um nexo de causalidade que é comprovado por uma lesão, doença ou problema de saúde já instalado. Alguns estudos, desenvolvidos em nosso pais, na última década, permitem situar e contextualisar a problemática de saúde vivenciada pelos trabalhadores de enfermagem como os realizados por Silva (1988), Barbosa (1989), Marzialle (1990), Alexandre (1993), Marzialle (1995), Souza (1995), Silva (1996 a), Silva (1996 b), Benatti (1997) e por Brevidelli (1997), Faria; Silva (1999).

Outros trabalhos, ainda relacionados com o desenvolvimento das atividades na enfermagem, que foram desenvolvidos por Machado et al. (1992), Souza; Vianna (1993) e Laurenti (1996); abordam uma preocupação com a saúde do trabalhador de enfermagem a partir da constatação do alto risco profissional que esse trabalhadoexposto e a relação com os acidentes de trabalho ocorridos com instrumentos perfurocortantes na sua vivência profissional.

A preocupaçăo verificada no pais com a saúde dos trabalhadores, demonstrada pelos estudos realizados é consonante com a preocupação também observada em outros paises ASSOCIATION FOR PRACTION IN INFECTION CONTROL (1993), CONTROLE DE INFECÇĀO (1994), JORNAL SBI (1995), Legge (1996), CONTROLE DE INFECÇÃO (1997), ENFERMAGEM (1997), Piza (1997), LIMPEZA (1998). Nestes paises a incidência de acidente de trabalho ocorridos com trabalhadores de enfermagem em relação aos outros profissionais também tem sido estudada.

$\mathrm{O}$ interesse pela questão do acidente de trabalho com instrumentos perfurocortantes tornou-se mais evidente quando a Sindrome da Imunodeficiência Adquirida-AIDS se expandiu, tornando-se uma pandemia. Alguns profissionais de saúde foram contaminados pelo virus da AIDS, o virus da imunodeficiência humana-HIV, no trabalho, somando 52 casos de soroconversão após exposição ocupacional (CDC, 1994). A transmissão do HIV em profissionais de saúde foi associada, principalmente, aos acidentes com instrumentos perfurocortantes (Cole, 1996). O risco médio de adquirir o HIV, segundo Ministério da Saúde, para todos os tipos de exposição percutânea é de $0,3 \%$ e pode aumentar, devido à carga viral, se o ferimento for profundo (CDC, 1996). Em relação à infecção pelo virus da hepatite B-HBV, Bulhões (1994) refere que $10 \%$ dos casos podem evoluir para uma forma fulminante da hepatite ou para uma forma crônica, como o carcinoma de figado e cirrose hepática. Para o $\mathrm{CDC}$, o risco de transmissão ocupacional da hepatite B após o acidente percutâneo é de (30\%). Afirma Cardo (1997), que vários estudos sobre a hepatite $B$ têm demonstrado que a prevalência deste virus é maior entre profissionais da saúde, quando comparados à população geral.

Na ocorrência do acidente, o Ministério da Saúde adota as recomendações do CDC do governo norte americano sobre quimioprofilaxia na exposição ocupacional ao HIV (BRASIL, 1997b), (CDC, 1998), porém a prevençăo de acidentes de trabalho é a medida que pode, mais significativamente, diminuir essa exposição ocupacional aos riscos biológicos e mecânicos inerentes ao trabalho.

Em 1970, o CDC publicou o manual intitulado "Técnicas de Isolamento em hospitais", mas cerca de (93\%) dos hospitais dos Estados Unidos não empregaram corretamente o uso destas práticas. Com o crescente aumento da possibilidade de exposição aos riscos ocupacionais, pela manipulação de sangue e fluidos orgânicos, o Centers for Disease Control 
O uso de equipamento de proteção...

de Atlanta, introduziu em 1985 um conjunto de práticas para garantir a segurança do profissional de saúde. Estas medidas foram chamadas precauções universais - PU. Em 1989, a Occupational Safety and Health Administration-OSHA, expressa a preocupação com os riscos que os trabalhadores de saúde estão submetidos, como afirma Garner (1996). O Guia Precauções de Isolamento em Hospitais foi reformulado e o conceito de precauções universais passa a ser identificado como precauções padrão. A prática das precauções padrão é baseada na barreira de transmissão e vem colaborar diretamente com a interrupção da transmissão de patógenos em hospitais (Garner, 1996). Estas precauçöes incluem o uso de barreiras para a proteção do profissional, como o uso de equipamentos de proteção individual-EPIs: avental, luvas, óculos, máscaras, gorros, e botas. Grande ênfase é dada para a lavagem das mãos e cuidados com instrumento perfurocortante (Cardo, 1997). Apesar da possibilidade de prevenção desses acidentes pelo uso destas precauções nem sempre são facilmente praticadas, pois ainda se observa um alto indice destes acidentes com sérias consequências. A incorporação na prática de enfermagem de instrumentos tecnologicamente avançados, que permitem prevenir estes acidentes, nem sempre é adotada pelas instituições.

Assim, a pouca atenção dispensada a essa problemática na prática, a grande freqüência de acidentes com perfurocortantes, a significativa não notificação desses acidentes e a necessidade de preveni-los, justificam a realizaçăo desse estudo que tem por objetivo: analisar os acidentes de trabalho ocorridos com trabalhadores de enfermagem, de um hospital público e geral, provocados por instrumentos perfurocortantes e o uso de equipamentos de proteção individual.

\section{METODOLOGIA}

O estudo caracterizou-se como exploratório, assumindo a forma de um estudo de caso, uma vez que objetiva tornar mais explicita a ocorrência do problema de acidente de trabalho com instrumentos perfurocortantes em uma instituição hospitalar especifica. A instituição campo de estudo foi um Hospital Público Universitário do interior do Estado de São Paulo. A população foi composta por todos os trabalhadores de enfermagem do referido hospital, que estavam trabalhando no periodo da coleta, totalizando 787 trabalhadores, sendo que 67 eram enfermeiros, 475 auxiliares de enfermagem e 245 atendentes de enfermagem. Destes 618 trabalhadores participaram do estudo. Inicialmente o projeto de estudo foi encaminhado ao Comitê de Ética em Pesquisa para a devida aprovação, conforme Resolução 196/96, respeitando o aspecto confidencial dos dados recebidos. A coleta de dados ocorreu no periodo de dezembro de 1997 a janeiro de 1998. Para tanto foi aplicado um questionário e, posteriormente, realizada entrevista. $\mathrm{O}$ dado considerado de interesse para o estudo foi o acidente de trabalho com instrumento perfurocortante e o uso de equipamentos de proteçăo individual. Os dados foram sistematizados segundo as freqüências relativa e absoluta e o coeficiente de risco-CR ${ }^{4}$, que estima a probabilidade destes trabalhadores sofrerem acidentes de trabalho.

\section{RESULTADOSEDISCUSSĀO}

Inicialmente, serão apresentados e discutidos todos os acidentes de trabalho ocorridos com os trabalhadores de enfermagem (tabela 1) e, posteriormente, os dados relativos aos trabalhadores de enfermagem que sofreram acidente de trabalho com instrumento perfurocortante, segundo categoria profissional, faixa etária, sexo, tipo de objeto causador e o uso de

\footnotetext{
${ }^{4} \mathrm{CR}=\underline{n^{\circ} \text { de vezes em que ocorre determinado evento }} \times 100$ $n^{\circ}$ de trabalhadores expostos ao evento
} 
equipamento de proteção em local de trabalho (tabelas 2 a 6).

TABELA 1 - FREQÜÊNCIA DE ACIDENTES OCORRIDOS COM TRABALHADORES DE ENFERMAGEM, SEGUNDO A CATEGORIA PROFISSIONAL, 1996

\begin{tabular}{|c|c|c|c|c|c|}
\hline \multirow[t]{2}{*}{ Categoria Profissional } & \multicolumn{2}{|c|}{$\begin{array}{c}\text { Total de } \\
\text { trabalhadores }\end{array}$} & \multicolumn{2}{|c|}{$\begin{array}{l}\text { Trabalhadores } \\
\text { acidentados }\end{array}$} & \multirow[t]{2}{*}{ CR } \\
\hline & $n^{\circ}$ & $\%$ & $\mathrm{~N}^{\circ}$ & $\%$ & \\
\hline Auxiliar de Enfermagem & 436 & 70,60 & 66 & 80,50 & 15,13 \\
\hline Atendente de Enfermagem. & 135 & 21,80 & 12 & 14,60 & 8,88 \\
\hline Enfermeiro & 47 & 7,60 & 4 & 4,90 & 8,51 \\
\hline Total & 618 & 100,00 & 82 & 100,00 & 13,26 \\
\hline
\end{tabular}

Nessa tabela, verificamos que a maior parte dos trabalhadores de enfermagem pertencem à categoria profissional auxiliar de enfermagem $(70,60 \%)$. Ao compararmos o contingente de trabalhadores acidentados, verificamos que houve variação na freqüência de acidentes, que pode ser analisada pelos coeficientes de risco.

Verificamos na categoria auxiliar de enfermagem, que o coeficiente de risco de acidentes de trabalho é quase o dobro das demais. Assim, vale acrescentar que a categoria de auxiliares de enfermagem desenvolve atividades muito próximas do paciente, e com acúmulo de atividades assistenciais, uma vez que assumem alguns procedimentos ou atividades, que anteriormente eram executado pelo atendente de enfermagem. Estes dados vem corroborar com os estudos de Souza; Vianna (1993), Escóssia (1998)e Siqueira et al. (1995).

TABELA 2 - FREQÜENNCIA DE ACIDENTES COM PERFUROCORTANTES, SEGUNDO CATEGORIA E FAIXA ETÁRIA, DOS TRABALHADORES DE ENFERMAGEM, 1996

\begin{tabular}{|c|c|c|c|c|c|c|c|c|c|c|c|c|}
\hline \multirow[t]{2}{*}{ Faixa Etária } & \multicolumn{3}{|c|}{ Enfermeiro } & \multicolumn{3}{|c|}{$\begin{array}{c}\text { Auxiliar de } \\
\text { Enfermagem }\end{array}$} & \multicolumn{3}{|c|}{ Atendente } & \multicolumn{3}{|c|}{ Total } \\
\hline & $n^{\circ}$ & $\%$ & $\mathrm{CR}$ & $\mathrm{n}^{\circ}$ & $\%$ & CR & $\mathrm{n}^{\circ}$ & $\%$ & CR & $n^{\circ}$ & $\%$ & $\mathrm{CR}$ \\
\hline $201-30$ & - & - & - & 9 & 19,14 & 8,49 & 2 & 4,25 & 1,48 & 11 & 23,40 & 10,37 \\
\hline $30-40$ & - & - & - & 22 & 46,81 & 8,14 & - & - & - & 22 & 46,81 & 8,14 \\
\hline $40-50$ & 1 & 2,12 & 6,25 & 11 & 23,40 & 5,55 & - & - & - & 12 & 25,53 & 6,06 \\
\hline $50-60$ & - & - & - & 2 & 4,25 & 4,54 & - & - & - & 2 & 4,25 & 4,54 \\
\hline Total & 1 & 2,12 & 2,12 & 44 & 93,60 & 10,09 & 2 & 4,25 & 1,48 & 47 & 100,00 & 7,60 \\
\hline
\end{tabular}

$\mathrm{Na}$ análise do acidente de trabalho segundo a categoria profissional, verificamos que quem mais se acidentou com instrumentos perfurocortantes foi o auxiliar de enfermagem, com um CR $=8,49$ acidentes. Autores, como Machado et al. (1992), Souza; Vianna (1993), Siqueira et al. (1995) e Escóssia (1998), relatam ser esta a categoria a que mais se acidenta com instrumento perfurocortante entre os trabalhadores de enfermagem.

Para os acidentes com perfurocortantes o maior coeficiente de risco é verificado na faixa etária de 20 a 30 anos. Observamos, também, que quanto maior a faixa etária,menor é o coeficiente de risco de acidentes com instrumento perfurocortante o que estaria relacionado com o desenvolvimento da habilidade para a prática, uma vez que o auxiliar de enfermagem começa trabalhar imediatamente após o curso, sem muita destreza e habilidade técnica.

Quanto à freqüência dos trabalhadores de enfermagem acidentados com perfurocortantes segundo o sexo, encontramos uma alta freqüencia no sexo feminino $(90 \%)$, enquanto para o sexo masculino esta freqüencia está em apenas $(10 \%)$. No coeficiente de risco segundo o sexo é, também, maior entre as trabalhadoras do sexo feminino com 8,43 acidentes, enquanto que para o sexo masculino, este coeficiente de risco se reduz para 4,16 acidentes/100 trabalhadores. 
$\mathrm{O}$ uso de equipamento de proteção...

O tipo de objeto causador que mais desencadeou acidente no trabalhador de enfermagem, encontra-se explicitiado nos dados abaixo.

TABELA3-DISTRIBUIÇÃO DOS ACIDENTES COM INSTRUMENTOS PERFURO-CORTANTES, SEGUNDO O TIPO DE OBJETO CAUSADOR, 1996

\begin{tabular}{lrr}
\hline Tipo de Objeto & $\mathrm{n}^{\circ}$ & $\%$ \\
\hline Perfurante & 26 & 52,00 \\
Agulha de injeção & 5 & 10,00 \\
Agulha de abocath & 2 & 4,00 \\
Agulha de scalp & 1 & 2,00 \\
Agulha de sutura & 1 & 2,00 \\
Agulha de cateter (uréter) & 35 & 70,00 \\
Subtotal & & \\
Cortante & & \\
Vidros (intermediário, pipeta, f. Aspiração, ampolas). & 10 & 20,00 \\
Lâmina de bisturi & 3 & 6,00 \\
Lâmina de barbear & 1 & 2,00 \\
Berço aquecido (lateral metálica) & 1 & 2,00 \\
Subtotal & 15 & 30,00 \\
\hline Total & 50 & 100,00
\end{tabular}

Pelos dados apresentados na Tabela 3 , encontramos que $70 \%$ dos acidentes com perfurocortantes ocorreram com objeto perfurante. Destes, as agulhas de injeção foram os mais freqüentes $(52,00 \%)$. Os objetos cortantes, representados pelos objetos de vidros (intermediários pipetas, frascos de aspiração e ampolas), ocorreram com uma porcentagem de 20,00\%. Nos estudos de Benatti (1997), Brevidelli (1997), Silva (1988), Silva (1996b), Shanks; Al-Kalai (1995), Thuler; Vaz (1994), e Yassil et al. (1991), também foram encontrados como a primeira causa de acidente de trabalho entre os trabalhadores de enfermagem o acidente com instrumento perfurante. Cardo (1997) afirma que entre todos os acidentes com instrumentos perfurocortantes, a agulha de injeção é o instrumento de trabalho que mais acomete a saúde do trabalhador de enfermagem. O ritmo acelerado de trabalho, a dupla jornada desenvolvida por alguns trabalhadores, podem comprometer a saúde desse trabalhador, pois são geradores de acidentes.

TABELA 4-DISTRIBUIÇÃO DO USO DE EQUIPAMENTO DE PROTEÇÃO INDIVIDUAL, ENTRE OS TRABALHADORES DE ENFERMAGEM ACIDENTADOS, SEGUNDO O TIPO, 1996

\begin{tabular}{|c|c|c|c|c|c|c|}
\hline \multirow[b]{2}{*}{$\begin{array}{l}\text { Equipamento de Proteção } \\
\text { Individual - EPI }\end{array}$} & \multicolumn{2}{|c|}{ Usava } & \multicolumn{2}{|c|}{ Não usava } & \multicolumn{2}{|c|}{ Total } \\
\hline & № & $\%$ & № & $\%$ & № & $\%$ \\
\hline Nenhum EPI & - & - & 25 & 46,29 & 25 & 46,29 \\
\hline Luvas & 21 & 38,89 & - & - & 21 & 38,89 \\
\hline Luvas e avental & 2 & 3,70 & - & - & 2 & 3,70 \\
\hline Máscaras e luvas & 1 & 1,85 & - & - & 1 & 1,85 \\
\hline Luvas, avental, gorro e máscara & 1 & 1,85 & - & - & 1 & 1,85 \\
\hline Não responder am & - & - & - & - & 4 & 7,42 \\
\hline Total & 25 & 46,29 & 25 & 46,29 & 54 & 100,00 \\
\hline
\end{tabular}


Verificamos, na tabela 4, que existe a mesma proporção de 46,26 \% entre o uso e não uso do equipamento de proteção individual no momento do acidente.

A utilização dos equipamentos de proteção individual $(46,29 \%)$ é muito importante, pois sabemos ser uma barreira de proteção que pode diminuir o contato com sangue, fluidos corpóreos e outros excretos, sendo que em algumas circunstâncias, reduzem significativamente a exposição aos riscos existentes no ambiente de trabalho (Wong et al.,1991 , Garner,1996). Porém, mesmo assim, encontramos a mesma proporção de trabalhadores que não faziam o uso do equipamento de proteçăo individual.

O uso de equipamento de proteção individual está regulamentado no artigo 166 da Lei número 6.514 de 22/12/77 (BRASIL, 1997a). Sabemos que o risco de acidente com perfurocortante, aumenta significativamente sem o uso dos equipamentos de proteção individual. Os dados deste estudo indicam que os equipamentos de proteção individual-EPIs, estavam disponiveis em todas as unidades do hospital e, mesmo assim, verificamos que metade destes trabalhadores năo estavam utilizando estes EPIs.

TABELA 5 - DISTRIBUIÇÄO DOS ACIDENTES DE TRABALHO COM PERFUROCORTANTES, SEGUNDO A DISPONIBILIDADE DOS EPIS NA UNIDADE DE TRABALHO, 1996

\begin{tabular}{lrr}
\hline \multicolumn{1}{c}{ Equipamento de Proteção Individual } & n-acidentes & $\%$ \\
\hline Luvas, máscaras, aventais, gorro, óculos, toca, sapatilha. & 45 & 79,62 \\
Somente luvas & 5 & 9,25 \\
Não responderam & 4 & 11,13 \\
\hline Total & 54 & 100,00 \\
\hline
\end{tabular}

Podemos visualizar na Tabela 5, que os EPIs estäo freqüentemente disponiveis para uso nas unidades $(79,62 \%)$, mesmo assim, em aproximadamente $20,00 \%$ das situaçōes, esta disponibilidade não existe, configurando o não atendimento das exigências legais. Por outro lado, como vimos na Tabela 4 , aproximadamente $46,00 \%$ dos trabalhadores que têm os equipamentos disponiveis não os utilizam e $9,25 \%$ relataram necessitar somente de luvas como material de proteção individual, dada especificidade dos procedimentos realizados.

Cardo; Bell(1997) e Rodrigues et al. (1996) afirmam que uma das medidas mais significativas para a reduçăo dos acidentes são medidas de precauçöes padrăo e reforçam que a sua prevenção, não se restringe simplesmente na observância dessas medidas, salientando outras medidas para evitá-los. Concluimos então, que os equipamentos de proteção estão disponiveis no hospital em estudo, porém os trabalhadores não os utilizam.

Os motivos alegados pelos trabalhadores acidentados para o não uso de equipamento de proteçăo individual, podem ser visualizados na Tabela 6:

TABELA 6 - DISTRIBUIÇĀO DOS MOTIVOS ALEGADOS PELOS TRABALHADORES PARA O NĀO USO DO EQUIPAMENTO DE PROTEÇÃO INDIVIDUAL PELOS TRABALHADORES DE ENFERMAGEM ACIDENTADOS COM PERFUROCORTANTES, 1996

\begin{tabular}{lrr}
\hline \multicolumn{1}{c}{ Motivos alegados pelo não uso do EPI } & $\mathrm{n}^{\circ} \mathbf{r}$ & $\%$ \\
\hline Desnecessário por não haver contaminação & 21 & 84,00 \\
Năo usava por estar em horário de descanso & 2 & 8,00 \\
Negligència pessoal & 1 & 4,00 \\
Ineficácia da luva & 1 & 4,00 \\
\hline Total & 25 & 100,00 \\
\hline
\end{tabular}

A maioria dos trabalhadores $(84,00 \%)$ julgam ser desnecessário o uso dos equipamentos 
de proteção individual, por acreditar não existir contaminação no material que manipulam. Sabemos que a barreira de proteção individual não impede o acidente, porém ajuda, significativamente, na menor exposição ao risco, conforme afirmam Machado et al. (1992), Systchenko (1996), Souza (1995) e Pustiglione (1998).

Rodrigues et al. (1996) procuraram compreender o significado do uso de equipamentos de proteção individual para o enfermeiro no seu cotidiano. Os resultados do estudo mostram que os enfermeiros conhecem a importância dessas medidas, entretanto, ao exercerem suas atividades, com o passar do tempo, sentem-se mais seguros de seus atos e, conseqüentemente, tendem a não utilização dessas medidas.

O uso desses equipamentos permite a realização de procedimentos de forma segura, tanto para o trabalhador, como para o cliente que está está prestando assistência (Machado et al.,1992, Henry; Campbell,1995, Ridzon,1997). Para Brevidelli (1997), os trabalhadores com maior experiência profissional precisam ter uma nova aprendizagem na utilização das medidas preventivas contidas nas precauçöes padrão

\section{CONCLUSÖES}

A categoria profissional auxiliar de enfermagem foi a categoria que mais sofreu acidente de trabalho, demonstrado pelo coeficiente de risco de $C R=15,13$ acidentes $/ 100$ trabalhadores. Quanto ao sexo, a composição da força de trabalho de enfermagem é, predominantemente, feminina $(80,59 \%)$. Também, a frequeência de acidentes é maior entre as mulheres, o que é demonstrado pelo coeficiente de risco de $\mathrm{CR}=3,85 / 100$ trabalhadoras e 10,83 acidentes $/ 100$ trabalhadores do sexo masculino. Entre todos os acidentes de trabalho o dano mais frequente foi o ferimento perfurante $(39,10 \%)$.

Em relação à frequeência dos acidentes com perfurocortantes, segundo a categoria e faixa etária, encontramos na categoria auxiliar de enfermagem o maior coeficiente de risco com $\mathrm{CR}=8,49$ acidentes $/ 100$ trabalhadores dessa categoria, com predominância na faixa etária jovem entre 20 a 30 anos. Constatamos que, quanto maior a faixa etária, menor é o coeficiente entre os trabalhadores de enfermagem.

Encontramos, ainda, que $70 \%$ desses acidentes ocorreram com objeto perfurante e que, destes, as agulhas de injeção foram as mais freqüentes $(52,00 \%)$. Já os acidentes com objetos cortantes são representados pelos objetos de vidro com um percentual de $20 \%$.

Constatamos que somente $50 \%$ dos trabalhadores usam os equipamentos de proteção individual, indicando que a metade dos trabalhadores de enfermagem não apreendem a real importância do uso desse equipamento. Verificamos, ainda, que $79,62 \%$ dos trabalhadores referem existir os equipamentos de proteção individual no local de trabalho.

Assim, podemos concluir, em vista dos resultados apresentados neste estudo, que os trabalhadores de enfermagem do Hospital foco de pesquisa, estăo expostos ao virus da AIDS e da hepatite $B$ no trabalho. Essa exposição pode ser apreendida pela alta freqüência de acidentes com perfurocortantes, sendo que ainda é reduzido o número de notificaçōes desses acidentes. Com isso, as possibilidades de prevenção com a quimioprofilaxia também são reduzidas, assim como as possibilidades de monitoramento e acompanhamento sorológico dos trabalhadores acidentados. Esse estudo indica, portanto, a necessidade de planejar intervenções estratégicas por parte das instituições e dos trabalhadores. Essas intervençőes devem focar as formas de organização/reorganização desse trabalho, buscando melhorar as condiçöes em que se realiza e a qualidade de vida dos trabalhadores.

ABSTRACT:The present study analyzed work related accidents involving nursing personnel from a public hospital in the state of São Paulo. The study population. comprised the entire nursing staff. The results obtained showed a high incidence of accidents with puncture-cutting instruments, particularly 
among the auxilliary nursing staff, which indicates that these workers don't often use individual protection equipment, even when it is made available at the work place. Due to the manipulation of sharp instruments, nursing personnel are especially vulnerable to suffer biological risks and serious diseases. These results indicate the need to prevent the occurrence of such accidents.

KEYWORDS: work accidents, sharp instruments, nursing personnel

RESUMEN: El presente estudio analizó los accidentes de trabajo que han ocurrido con trabajadores de enfermeria en un hospital público del interior de Săo Paulo. La muestra se ha compuesto por todos los trabajadores de enfermeria. Los resultados obtenidos muestran la significativa frecuencia de accidentes con instrumentos perfurocortantes. En ese tipo de accidente, los más graves están en la categoria de auxiliares de enfermeria, lo que demuestra también que muchas veces el trabajador no utiliza los equipos de protección individual, aunque se les dé en el local de trabajo. La manipulación de instrumentos perfurocortantes por los profesionales del área muestra una gran exposición a los riesgos biológicos y a las graves enfermedades. Esos resultados evidencian la necesidad de prevenir tales accidentes.

PALABRAS CLAVE: accidentes de trabajo, instrumental perfurocortantes, enfermeria

\section{REFERÊNCIAS BIBLIOGRÁFICAS}

ALEXANDRE, N. M. C. Contribuição ao estudo das cérvicodorsolombalgias em profissionais de enfermagem. 1993. 186 p. Tese (Doutorado) Escola de Enfermagem de Ribeirāo Preto, Universidade de São Paulo, Ribeiräo Preto.

ASSOCIATION FOR PRACTITION IN INFECTION CONTROL. APIC position paper: prevention of devidemediated blood-borne infections to healt care workers. Am. J. Infect Control, v. 21, n.2, p. 76-8, 1993.

BARBOSA, A. Riscos ocupacionais em hospitais: um desafio aos profissionais da área de saúde ocupacional. 1989. 126p. Dissertaçāo (Mestrado) Departamento de Enfermagem, Universidade Federal de Santa Catarina, Florianópolis.

BENATTI, M. C. C. Acidente de trabalho em um hospital universitário: um estudo sobre a ocorrência e os fatores de risco entre trabalhadores de enfermagem. 1997. 239 p. Tese (Doutorado) Escola Enfermagem de Ribeirão Preto, Universidade de São Paulo, São Paulo.

BRASIL. Leis etc. Lei n 6.514 de 22 de dezembro de 1977 e Portaria n 3.214 de 08 de junho de 1978 : normas regulamentadoras. Segurança e medicina do trabalho. São Paulo: Atlas, 1997a. p.4 - 97.

BRASIL. Ministério da Saủde. Guia de condutas terapêuticas em HIVIAIDS. Brasilia,1997b.

BREVIDELLI, M. M. Exposição ocupacional ao virus da AIDS e da hepatite B: análise da influência das crenças em saúde sobre a prática de reencapar agulhas. São Paulo, 1997. Dissertação (Mestrado)Escola de Enfermagem , Universidade de São Paulo, São Paulo.

BULHŐES, I. Riscos do trabalho de enfermagem. Rio de Janeiro, 1994.

CARDO, D M; BELL, D. M. Bloodborne pathogen transmission in health care workers: risks and prevention strategies. Infect. Dis. Clin. North. Am. v.11, n.2, p.331 - 46, 1997.

CARDO, D. M. Patógenos veiculados pelo sangue. In: RODRIGUES, E. A. C. et al. Infecçöes hospitalares prevenção e controle. São Paulo: Sarvier, 1997. Parte 4, p. 341 - 51. 
O uso de equipamento de proteção...

CENTERS FOR DISEASE CONTROL. Occupational exposure to HIV information for health-care workers. [on line ]. Disponivel na internet: http://www.cdc.gov. (04 mar.1998).

CENTERS FOR DISEASE CONTROL. Public health service guidelines for the management of healthcare worker exposures to HIV and recomendations for postexposure prophylaxis. [on line]. MMWR Morb. Mortal. Wkly. Rep., v. 47, n. R.R.-7, p.1-33, 1998.Disponivel na Internet: http://www.cdc.gov (18 jul. 1998).

CENTERS FOR DISEASE CONTROL: provisional public health services recomendations for chemoprophylasis transmission in health care settings. MMWR Morb. Mortal. Wkly. Rep., v.45, n.22, p. 468-72, 1996.

CENTERS FOR DISEASE CONTROL. U. S. health-care workers whith documented and possible accupationally acquired HIV infection. MMWR Morb. Mortal. Wkly. Rep., v. 6, n. 21, 1994.

COLE, F. L. Factors associated with student nurses' intent to provide physical and psychosocial care to persons whit acquired immunodeficiency syndrome. J. Prof. Nurs. v.12, n.4, p. $217-24,1996$.

CONTROLE DE INFECÇÃO, São Paulo, v. 6, n. 23, 1994.

CONTROLE DE INFECÇÃO, São Paulo, v. 8, n. 34, 1997.

ENFERMAGEM Profissão de risco e de desgaste. Nursing, abril, 1997. Disponivel na Internet: http:// www.f.bento.pt/nur/0397/a 02-00-oo.html.(24 ago.1997).

ESCÓSSIA, F. da; Erros básicos causam acidentes em hospital. Folha de São Paulo, 20 jun. 1998. Caderno Cotidiano, 3, p. 3.

FARIA, L. S.; SILVA, V. E. F. da. Os riscos fisiológicos e psiquicos identificados entre os trabalhadores de enfermagem em um centro de reabilitação. In: SEMINÁRIO DE PESQUISA EM ENFERMAGEM, 10. Gramado, 1999. Programa... Gramado: ABEn-Seção-RS, 1999. p. 184./Resumo/.

GARNER, J. S. Guideline for isolation precaUnidade de Terapia Intensivaon in hospitals. Infect. Control Hosp. Epidemiol., v. 17, n. 1, p. 53-80, 1996.

HENRY, K. ; CAMPBELL, S. Needlestickharps injuries and HIV exposure among health care workers. National estimates based on a survey of U. S. hospitals. Minn. Med., v. 78, n. 11, p. 41-4. 1995.

JORNAL SBI - INFORMATIVO DA SOCIEDADE BRASILEIRA DE INFECTOLOGIA. Acidentes com agulhas merecem atenção cada vez maior, São Paulo. v. 4, n. 4, dez. 1995. p.1.

LAURENTI, L. O desgaste profissional do enfermeiro. In: CONGRESSO BRASILEIRO DE ENFERMAGEM, 48, São Paulo, 1996. Programa. São Paulo, ABEN-Seção - SP, 1996, p. 231. I Resumo/.

LEGGE, A, Sharps disposal systems. Prof. Nurse., v.12, n.1, p. 57-62, 1996.

LIMPEZA e saúde são profissões de risco. Nursing, Lisboa, v.10, n. 119, 1998 [on line]. Disponivel na Internet: <http: //www.fbento.pt/nur>.

MACHADO, .A. A.,COSTA, J.C. ;GIR,E. ;MORYTA,T.M. ;FIGUEIREDO, J.F.C. Risco de infeç̧äo pelo virus da imunodeficiência humana (HIV) em profissionais de saúde. Rev. Saúde Pública, v. 26, n. 1, p. 54 $-6,1992$.

MARZIALE, M. H. P. Condiçöes ergonômicas da situação de trabalho, do pessoal da enfermagem, em uma unidade de internação hospitalar. 1995. 163p. Tese (Doutorado) - Escola de Enfermagem de Ribeirão Preto, Universidade de São Paulo, Ribeiräo Preto. 
MARZIALE, M. H. P. Estudo da fadiga mental de enfermeiras atuantes em instituição hospitalar com esquema de trabalho em turnos altemantes. 1990, 132 p. Dissertação (Mestrado) Faculdade de Filosofia de Ciências e Letras de Ribeirāo Preto, Universidade de São Paulo, Ribeirāo Preto.

PIZA, F. T. Informaçōes básicas sobre saúde e segurança no trabalho. São Paulo: CIPA, 1997. p. 3436 : Equipamento de proteçăo individual.

PUSTIGLIONE, M. HIVIAIDS e o trabalho. Mundo Saúde, v.22, n.5, p.280-2, 1998.

RIDZON, R; et al. Simultaneous transmission of human immunodeficiency virus and hepatitis $\mathrm{C}$ virus from a needle-stick injury. News Engl. J. Med. v. 336, n. 13, p. 919-22, 1997.

RODRIGUES, A. E. et al. Medidas de precauções universais: compreendendo o seu significado no cotidiano do enfermeiro. In: CONGRESSO BRASILEIRO DE ENFERMAGEM, 48, Säo Paulo, 1996. Programa... São Paulo: ABEN-Seção-SP, 1996. p. 237./Resumo/.

SHANKS, N. J ; AL - KALAI, D. Occupation risk of needlestick injuries among health care personnel in Sandi Arabia. J. Hosp. Infect., v. 29, n. 3, p. 221 - 6, 1995.

SILVA, A. Trabalhador de enfermagem na Unidade de Centro de Material e os acidentes de trabalho. 1996a 192 p. Tese (Doutorado) - Escola de Enfermagem, Universidade de São Paulo, Säo Paulo.

SILVA, V. E. F. da O desgaste do trabalhador de enfermagem: estudo da relação trabalho de enfermagem e saúde do trabalhador. 1996b. 289 p. Tese (Doutorado) - Escola de enfermagem, Universidade de São Paulo, Sāo Paulo.

SILVA, V. E. F. da, Estudo sobre acidentes de trabalho ocorridos com trabalhadores de enfermagem de um hospital de ensino. 1988, 203 p. Dissertação (Mestrado) - Escola de Enfermagem - Universidade de São Paulo, São Paulo.

SIQUEIRA, M. M. de; WATANABE, F. S. ; VENTOLA, A. Desgaste físico e mental de auxiliares de enfermagem: uma análise sob o enfoque gerencial. Rev. Lat. Am. Enf., v. 3, n.1, p. 45 - 57, 1995.

SOUZA, M. de Conhecimento e aplicação das precauções universais pelos componentes da equipe de enfermagem de um hospital govemamental. 1995. 165p. Dissertaçăo (Mestrado) -Escola Paulista de Medicina, Universidade Federal de São Paulo, São Paulo.

SOUZA, M.; VIANNA, L. A. C. Incidência de acidentes de trabalho relacionada com a não utilizaçāo das precauçōes universais. Rev. Bras. Enf., v.46, n.3/4, p.234-44,1993.

SYSTCHENKO, B. et al. Hepatitis C: risc for hospital staff. Arch. Mal. Prof. Med. Trav., v.57, n.18, p.1-8, 1996.

THULER, L. C. S.; VAZ, L. F. G. Infecção pelo HIV. J. Bras. Med., v. 66, n.3, p. 85-108, 1994.

WONG, E. S. et al. Are universal precautions effective in reducing the number of occupational exposures among health care workers? A prospective study of phisicans on a medical service. JAMA, v. 265, n. 9 , p. $1123-27,1991$.

YASSI, A. et al. Determinants of blood and body fluid exposure in a large teaching hospital: hazards of the intermittent intravenous procedure. Am. J. Infect. Control., v. 19, v. 3, p. 129 - 35, 1991.

Recebido em junho de 2000

Aprovado em junho de 2001 